\title{
Computers, Internet and Smartphone Attitudes Among Romanian University Students
}

\author{
Cătălin loan Maican
}

Elena Cocoradă

Transilvania University of Braşov

\begin{abstract}
Higher education institutions encourage the use of computers and of the internet for accessing content, assignments, exam results and collaborative learning work. Our study focuses on the university students' attitudes towards the use of computers, internet and smartphones in relationship with the field of studies, age, gender, academic performance. The research is a descriptive and correlational one. The participants were 685 female and male university students, enrolled in Sciences and Humanities, distributed in two studies which conducted at a distance of four years. The instruments used were the following: CARS, (Heinssen, Glass, \& Knight, 1987), the IAS (Nickel and Pinto (1986), CAS (Compeau, \& Higgins, 1995), some scales of MTUAS (Rosen, Whaling, Carrier, Cheever, \& Rokkum, 2013) and of USLS (Rung, Wranke, and Mattheos, 2014). The results showed significant differences between male and female students concerning the use and attitudes towards computers, internet and smartphones. But the self-efficacy is the same with males and females, conventional and nonconventional students, respectively. The positive and negative attitudes and task switching are equal for the two genders, and the academic performance is associated with a part of the activities performed on Facebook. The findings are discussed in connection with the learning situations, the multitasking tendencies and the use of technologies for social and private activities.
\end{abstract}

Keywords: Computers, Internet and Smartphone Attitudes Among Romanian University Students

\section{Introduction}

\subsection{Attitude characteristics}

Attitude was defined by Allport as a mental state of training, organized by experience, which directs and dynamically influences the individual's response to all the objects and situations with which it is related. In this approach, an attitude appears as a unity of cognitive, affective and behavioural elements (1935). In the context of our research, the attitudes include anxiety or confidence, anger, fear or good mood, preference or rejection, tendency to use or avoid attitudinal objects, statements of likes or dislikes about some activities or objects.

\subsection{The research context}

In Romania, high school and university students represent a substantial part of the contributors to the increase in the use of computers, internet and smartphones. On the average, students spend more than an hour of their free time on the computer, males -67 minutes and females -58 minutes. Only $10 \%$ of the people aged 16 to 34 have not used a computer (National Institute of Statistics, 2013).

In the latest years, the rate of smartphone penetration in our country is $158 \%$ per total population and this device is used more for accessing the internet and social networking sites. The most popular social networking site is Facebook with over 8.8 mil users, among whom approximatively $32.8 \%$ are young people in the age range 13-24 years (Forrester Research, 2016), thus representing a significant part of the students' population.

Our study focuses on the university students' attitudes concerning the use of computers, internet and smartphones in relationship with the field of studies, age, gender, academic performance. The research was conducted in two steps: the first study in 2012-2013 (focused on the computer and the internet), and the second study in 2016 (focused on the smartphone and its apps). 


\section{Study 1}

\subsection{Short literature review}

Over the recent period, more and more universities encourage the use of the computers and the internet to access courses, syllabi, assignments, readings, grades or remote laboratories. Especially for distance learning, but for face-to-face education as well, electronic platforms were built that deliver content and tools for learning. The usage of these tools is marked by the students' confidence and favourable evaluation, or by the opposite, anxiety or rejection.

In different cultures, the first studies on the attitudes towards computer showed that females and elderly people, more than males and the youth, have a negative perception and experience negative feelings towards the computer and the internet, expressed in avoidance and distress. Male students have more computer/technology experience than female ones (e.g. Cooper, 2006) and more positive perceptions towards computers and the web (e.g. Weil, \& Rosen, 1995; Liaw, 2002). The findings are not all convergent: in Turkey, research revealed that males appeared to be more computer anxious than their female co-twins (e.g. Deryakulu \& Calışkan, 2012). Lower levels of computer anxiety were directly related to math anxiety, higher computer experience levels and mechanical interest (e.g. Heinssen, Glass, \& Knight, 1987, Marcoulides, Cavus, Marcoulides, \& Gunbatar, 2009).

The results of various research studies showed a significant positive correlation between attitudes towards computers and towards the web (e.g. Liaw, 2002; Rotsztein, 2003). Recent studies confirm that gender and personality traits would moderate the online social networking behaviour, also having a significant impact on the adoption of different types of mobile apps (e.g. Muscanell \& Guadagno, 2012; Xu, Frey, Fleisch, \& llic, 2016). The frequent use of the internet is associated in the case of students with a minimal deficiency in their lives, socially, academically or life-style wise.

\subsection{Research methodology}

\section{Objective and hypothesis}

The first research study aims at analysing university students' attitudes towards the computers and the internet in connection with their age, gender, field of studies and academic performance. Our hypotheses were (1) the anxiety towards computers and the internet is lower for males, young students and those enrolled in Sciences; (2) self-efficacy is lower for females, older students and those enrolled in Humanities; (3) computer anxiety and self-efficacy are negatively correlated, and (4) computer and internet anxiety are negatively correlated with academic performance.

\section{Participants}

Our first research comprised 318 students, female $(76 \%)$ and male, with a mean age of 23 years $(S D=6.1)$. Among these, $48 \%$ are enrolled in Humanities and the others in Sciences. Regular or conventional students (aged under 25) represent $77 \%$, the others being over 25 years old. $97.5 \%$ own a computer, but the number of years dedicated to the study of ICT varies: $51.8 \%$ participants studied ICT between 4 and 6 years, $12 \%$ did not study at all, but learned by themselves. The mean number of the years of study for ICT subjects is 4.4 for the entire sample. The time span for using the computer varies from 1 to 21 years, the mean being 9.9 years.

\section{Instruments}

The following instruments were used: the Computer Anxiety Rating Scale (CARS), the Internet Attitude Scale (IAS) and the Computer Self-Efficacy Scale (CSE). The Computer Anxiety Rating Scale is a self-report inventory elaborated by Heinssen, Glass, \& Knight (1987) with 19 items and was used here with a four-option Likert scale (1=strongly disagree, 2=disagree, $3=$ agree, and 4=strongly agree). The total scores ranged from 19 to 76 . Low scores indicate a low level of computer anxiety.

The Internet Attitude Scale (IAS) is a tool to assess the attitude towards the internet, consisting of 18 items used with a five-point Likert scale (alpha Cronbach=0.80 for 18 items). Low scores indicate a low level of internet anxiety.

The Computer Self-Efficacy Scale elaborated in 1995 by Compeau and Higgins, is a 10 items tool which assesses the selfefficacy in the computer field on a ten points Likert scale (1=strongly distrustful and 10=strongly trustful). We have grouped the items into two factors: Assisted self-efficacy and Independent self-efficacy (Cocoradă \& Pălăşan, 2014). Low scores indicate a low level of self-efficacy towards the computer. A socio-demographic questionnaire was used. 


\subsection{Results}

Gender and age differences regarding computer and internet anxiety are significant, but the ones related to self-efficacy with males and females, with conventional and non-conventional students, respectively, do not reach the threshold of statistical significance. The anxiety towards the computer and the internet are lower for males and young students, but selfefficacy is not lower for female and older students compared with male and younger students (Table 1).

Table 1 Gender and age differences concerning computer and internet anxiety, and self-efficacy towards the computer

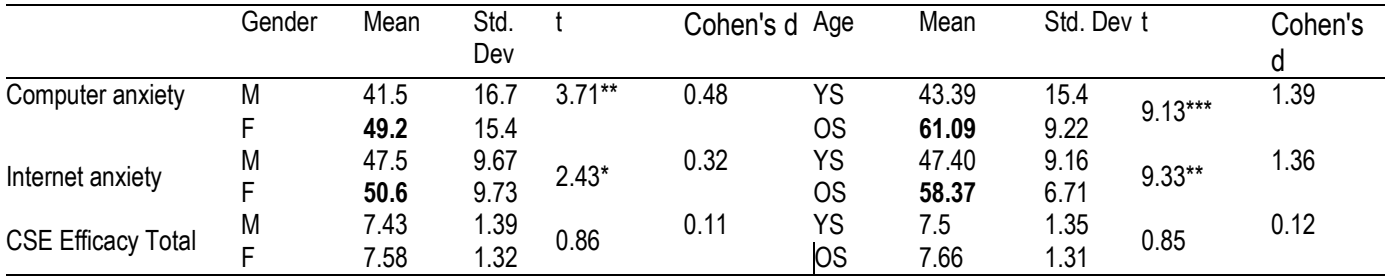

Note: Female $=243$, male=74,

YS- Younger students $<25$ years $=246$, OS- Old students $>25$ years $=71$

${ }^{* * *} p<.001,{ }^{* *} p<.01$

The specialization introduces statistically significant differences: the students in Sciences are less anxious, have more favourable attitudes towards the internet compared to those from the Humanities $(t=44.2, p<.0001, t=26.03, p<.0001$, respectively). The students in Humanities have a greater sense of efficacy than those in Sciences $(r=2.96, p<.01)$. The way students learned to use the computers, alone or at school, does not introduce significant differences in the three variables studied (Table 2).

Table 2 Differences concerning computer and internet anxiety, and self-efficacy towards the computer depending on specialization and way of learning

\begin{tabular}{|c|c|c|c|c|c|c|c|c|c|c|}
\hline & Profile & Mean & Std. De & $t$ & Cohen's d & $\begin{array}{l}\text { Way of } \\
\text { learning }\end{array}$ & Mean & Std. Dev. & $t$ & Cohen's d \\
\hline Computer & $\mathrm{H}$ & 62.9 & 5.95 & $44.2^{\star \star *}$ & 4.96 & Informal & 45.26 & 14.4 & 1.03 & 0.30 \\
\hline anxiety & S & 33.2 & 6.01 & & & Formal & 41.2 & 12.06 & & \\
\hline Internet attitude & $\begin{array}{l}\mathrm{H} \\
\mathrm{S}\end{array}$ & $\begin{array}{l}\mathbf{5 8 . 3} \\
42.2\end{array}$ & $\begin{array}{l}5.6 \\
5.43\end{array}$ & $26.03^{* * *}$ & 2.91 & $\begin{array}{l}\text { Informal } \\
\text { Formal }\end{array}$ & $\begin{array}{l}49.36 \\
47.3\end{array}$ & $\begin{array}{l}8.09 \\
7.7\end{array}$ & 0.81 & 0.26 \\
\hline Self-efficacy & $\begin{array}{l}\mathrm{H} \\
\mathrm{S}\end{array}$ & $\begin{array}{l}7.78 \\
7.33\end{array}$ & $\begin{array}{l}1.25 \\
1.4\end{array}$ & $2.96^{* *}$ & 0.34 & $\begin{array}{l}\text { Informal } \\
\text { Formal }\end{array}$ & $\begin{array}{l}7.75 \\
7.09\end{array}$ & $\begin{array}{l}1.26 \\
1.62\end{array}$ & 1.47 & 0.53 \\
\hline
\end{tabular}

Note: Sciences $(S)=166$, Humanities $(H)=152 ;$ Informal $=185$, Formal $=133$,

${ }^{* * *} p<.001,{ }^{* *} p<.01$

Computer and internet anxiety are directly and strongly associated $(r=0.87)$, and both are associated with age $(r=0.42)$, the coefficients being significant at high level. Computer and internet anxiety are negatively associated with academic performance for ICT subjects $(r=-0.29, p<0.001, r=-0.26, p<0.001$, respectively). There are no significant associations of the two types of anxiety with the students' GPA (Table 3 ).

Table 3 Correlations between academic performance and computer and internet anxiety, and self-efficacy

\begin{tabular}{|c|c|c|c|c|c|}
\hline & $\begin{array}{l}\text { Computer } \\
\text { anxiety }\end{array}$ & $\begin{array}{l}\text { Internet } \\
\text { anxiety }\end{array}$ & Age & $\begin{array}{l}\text { Number of years GPA previous } \\
\text { of ICT study semester }\end{array}$ & $\begin{array}{l}\text { ICT grade for the } \\
\text { previous semester }\end{array}$ \\
\hline Computer anxiety & 1 & & & & \\
\hline Internet anxiety & $0.875^{\star * *}$ & 1 & & & \\
\hline Age & $0.419^{* * *}$ & $0.422^{* *}$ & 1 & & \\
\hline Number of years of ICT study & $-0.131^{*}$ & $-0.118^{*}$ & $-0.338^{* * *}$ & 1 & \\
\hline
\end{tabular}




\begin{tabular}{lllllll} 
GPA previous semester & 0.135 & 0.107 & 0.095 & -0.024 & 1 & \\
$\begin{array}{l}\text { ICT grade for the previous } \\
\text { semester }\end{array}$ & $0.290^{* * *}$ & $0.258^{* * *}$ & $0.145^{*}$ & 0.041 & $0.629^{* * *}$ & 1 \\
\hline
\end{tabular}

Note: ${ }^{*} p<0.05$ level (2-tailed), ${ }^{* *} p<.01$ level (2-tailed), ${ }^{* * *} p<.001$ level (2-tailed).

\section{4 Discussion}

Our findings revealed a significant positive correlation between computer attitudes and web attitudes, confirming other studies (e.g. Liaw, 2002). According to our assumption, the anxiety towards the computer and the internet is lower in the case of males and young students, but the self-efficacy is not lower for female and older students. The higher anxiety level present with female students can be explained by their strong emotional response, the perceptions of threat in evaluative situations, or by less experience with computer. Students in the Science profile are less anxious, have more favourable attitudes towards the internet than those in the Humanities, confirming the positive impact of skills and interests over anxiety (Marcoulides et al., 2009). The students from the Humanist profile, however, have a greater sense of efficacy than those in the Science profile, which is probably explained by the lower difficulty of the ICT subjects found in the curriculum for the Humanist field.

The age heterogeneity of our sample permits us to underline the influence of the age: older students are more anxious compared to younger ones. In contrast with others studies, in our sample there are not differences in point of self efficacy believes between older and younger students. The way they learned how to use the computer, alone or at school, does not indicate significant differences on this sample. The students with the highest computer and internet anxiety have lower academic performance with respect to ICT subjects, but we could not identify correlations with the GPA. So, our findings confirm only a part of past studies, highlighting the importance of cultural context and the research decade.

\section{Study 2}

\subsection{Short literature review}

Some findings concerning the ownership of the smartphone showed the tendency for the owners to be younger, male and have a higher level of education. As users, females prefer the texting function, while male and older students prefer information seeking (e.g. Mayudia et al., 2013). The participants in the research who preferred to task switch showed greater usage of smartphones, greater general Facebook usage, more internet searching, greater e-mail use, more media sharing, more text messaging, more video gaming and more phone calling.

Except for television viewing, Facebook users showed use of nearly all technologies (e.g. Rosen et al., 2013). Some findings showed that the students used the phones much less for education purposes and much more for leisure (e.g. Lepp, Barkley, \& Karpinski, 2015 ).

The results of smartphone and Facebook usage in education are mixed: some studies show that students use Facebook less for educational purposes and much more for communicating with friends, no direct link being detected between the use of social networks and the students' academic performance (Hew, 2011). Other studies revealed that some dimensions of Facebook usage are correlated with the students' performances (e.g. Wohn \& LaRose, 2014) or reported a negative correlation between Facebook usage and student performances (e.g. Junco, 2012).

Some studies confirm that gender and personality traits have a significant impact on the adoption of smartphone apps or Facebook activities (Gosling, Augustine, Vazire, Holtzman, \& Gaddis, 2011; Xu et al., 2016).

Concerning the anxiety without technology, an emerging problem of modern times, the studies showed that both males and females were found to be nomophobic in a group of students, with males more than females. The subjects tend to be anxious when they have no network coverage, lose their mobile phone, run out of battery or credit (e.g. Dixit, et al., 2010).

\subsection{Research methodology}

\section{Objective and hypothesis}

The research aimed at analysing university students' attitudes towards new technologies. Our hypotheses were: (1) the attitudes of the participants towards the technology are positive and negative (mixed), (2) the anxiety without technology is 
higher in the case of males and younger students; (3) smartphone applications are differently used by female and male students, and differently by students in Sciences and Humanities and (4) there is an association between the attitudes towards technology and academic performance.

\section{Participants}

Our research comprised 420 female $(70 \%)$ and male students, with an average age of 22.4 years $(S D=5.1)$. Of these, $57 \%$ are enrolled in the humanist profile, the others in the Science profile. Conventional students (aged under 25) account for $70 \%$, while others are older than 25 years.

\section{Instruments}

The instruments used are Media and Technology Usage and Attitudes Scale - MTUAS (Rosen et al., 2013), Part B of the Use of Smartphones for Learning Purposes Scale-USLS (Rung, Wranke, and Mattheos, 2014). This part explores only the use of the smartphone for learning purposes, including the use of social media for learning.

From MTUAS, only part three was used in this research, including the four factors labelled Anxiety without technology, Positive attitude, Negative attitude and Task switching. The scale called Anxiety without technology includes three items related to the people's having no access to a phone or the internet, and as a consequence, to technological dependence (Rosen et al., 2013). A socio-demographic questionnaire was used.

\subsection{Results}

$97.5 \%$ of the participants own a smartphone, while $51.8 \%$ of the participants studied ICT at school between 4 and 6 years, $12 \%$ did not study it at all, the average of the years of study dedicated to ICT subjects on the whole sample being 4.4 years. The time they used the computer varies from one year to 21 years, the average for the sample being 9.9 years. The smartphone usage time is $5.08(S D=3.7)$, with no significant differences between female and male students.

The participants, females and males, report negative and positive attitudes, the dependence on new technology and the switch between tasks being equal for both genders. The specialization introduces statistically significant differences in the negative attitudes towards technology, which are more pronounced in the case of the students in Sciences, while task switching is more common in the Humanities at a marginal significance level 0.07 (Table 4).

Table 4 Gender and specialization differences concerning the attitudes towards technology

\begin{tabular}{|c|c|c|c|c|c|c|c|c|c|c|}
\hline & Gender & Mean & Std. & & Cohe & $\begin{array}{l}\text { Faculty } \\
\text { profile }\end{array}$ & Mean & Std. Dev. & $t$ & Cohen's d \\
\hline \multirow{2}{*}{$\begin{array}{l}\text { Anxiety without } \\
\text { technology }\end{array}$} & $F$ & 9.30 & 2.93 & $2.1^{*}$ & 0.33 & $\mathrm{H}$ & 9.48 & 2.99 & 1.56 & 0.001 \\
\hline & M & 10.2 & 2.50 & & & $S$ & 9.49 & 2.61 & & \\
\hline \multirow{2}{*}{ Negative attitudes } & $F$ & 7.99 & 2.78 & 0.16 & 0.02 & $\mathrm{H}$ & 7.54 & 2.64 & $3.82^{* *}$ & 0.49 \\
\hline & $M$ & 8.06 & 2.85 & & & S & 8.89 & 2.84 & & \\
\hline \multirow{2}{*}{$\begin{array}{l}\text { Positive attitudes } \\
\text { towards technology }\end{array}$} & $F$ & 10.59 & 3.11 & 0.24 & 0.03 & $\mathrm{H}$ & 10.39 & 2.89 & 1.31 & 0.17 \\
\hline & M & 10.5 & 2.93 & & & $S$ & 10.92 & 3.36 & & \\
\hline \multirow{2}{*}{ Task switching } & $\mathrm{F}$ & 14.03 & 3.64 & 0.57 & 0.1 & $\mathrm{H}$ & 14.37 & 3.54 & 1.08 & 0.23 \\
\hline & M & 14.4 & 4.01 & & & S & 13.52 & 3.95 & & \\
\hline
\end{tabular}

Note: ${ }^{*} p<0.05$ level (2-tailed), ${ }^{* *} p<.01$ level (2-tailed).

Depending on age, there are no statistically significant differences in the attitudes towards new technologies. Students more addicted to new technologies have more positive attitudes towards them $(r=.33, p<.01)$ and switch more frequently between tasks $(r=.22, p<.001)$. Students with more negative attitudes are less dependent on new technologies $(r=.22$, $\mathrm{p}<.001)$.

Male student and students enrolled in the Science profile declare that they use the smartphone for learning more compared to females and the students from humanist profile $(t=3.54, p<.01)$. Smartphone applications are differently used by the two genders and the two profiles, the differences being significant only for three applications (Table 5). 
Table 5 Gender differences concerning the usage of smartphone applications

\begin{tabular}{|c|c|c|c|c|c|}
\hline & Gender & Mean & Std. Dev. & $t$ & Cohen's d \\
\hline \multirow{2}{*}{ Listen to music? } & M & 0.90 & 0.30 & \multirow{2}{*}{$\begin{array}{l}1.86 \\
\text { Marginal sig. } 0.06\end{array}$} & \multirow[t]{2}{*}{0.20} \\
\hline & $\mathrm{F}$ & 0.83 & 0.38 & & \\
\hline \multirow{2}{*}{ Editing photos? } & M & 0.39 & 0.49 & \multirow{2}{*}{$4.66^{* \star *}$} & \multirow[t]{2}{*}{0.49} \\
\hline & $\mathrm{F}$ & 0.63 & 0.48 & & \\
\hline \multirow{2}{*}{ Sync with the PC? } & M & 0.56 & 0.49 & \multirow{2}{*}{$1.99^{*}$} & \multirow[t]{2}{*}{0.22} \\
\hline & $F$ & 0.45 & 0.50 & & \\
\hline \multirow{2}{*}{ Learning Smartphone Total } & M & 3.02 & 0.75 & \multirow{2}{*}{$\beta .54^{\star *}$} & \multirow[t]{2}{*}{0.65} \\
\hline & $\mathrm{F}$ & 2.73 & 0.76 & & \\
\hline
\end{tabular}

Note: $M=121, F=299 ; p<0.05$ level (2-tailed), ${ }^{* *} p<0.01$ level (2-tailed), ${ }^{* * *} p<0.001$ level

The lowest scores for using smartphone applications are related to creating animations and drawings, editing movies, while the highest are related to conversations with friends, shooting, listening to music. With respect to Facebook activities, there are statistically significant gender differences only with respect to checking pages from school or from work (Mean females $=$ 6.8 , Meanmales $=6.3, t=1.78, p=0.06$ ), to where they check them, to reading posts (Meanfemales $=7.12$, Mean males $_{\text {en }}=6.75, t$ $=1.67, p=0.08$ ) and liking posts and photos ( Mean $_{\text {females }}=6.82$, Mean $_{\text {males }}=6.31, t=2.1, p=0.05$ ). Females tend to be more active, but there are no differences regarding these activities from the perspectives of the studied profile. Some activities carried by the participants correlate negatively and weakly, but significantly with the GPA: looking for profiles of other users $(r=-0.13, p=0.01)$ and looking for friends on Facebook $(r=-0.125, p<0.01)$.

\section{4 Discussions}

Most of the investigated students own a smartphone, confirming the idea of this device being owned by more highly educated people. On this sample, the smartphone is equally present in females and males, younger and older students. Negative and positive attitudes and dependence on listed technology are reported to the same extent by both female and male students, so the first hypothesis is confirmed. Depending on age, there are no statistically significant differences in the attitudes towards the use of this device. Negative attitudes towards new technologies are more prominent for Science students, while task switching is more common in Humanities students. Contrary to the data obtained from other studies (e.g. Mayudia et al., 2013), in our sample, the students who switch tasks do not report that they would use the smartphone more frequently, but they use only video games more often. According to other studies (e.g. Dixit et al., 2010) in our study, the anxiety without technology is higher in male students.

Smartphone applications are differently used by female and male students: the former edit more photos, while the latter listen to music and synchronize their phone with the PC. Male students and students enrolled in the Science profile say they use more the smartphone for learning, compared to girls and Humanities students. Difficult cognitive applications are less used (e.g. creating animations and drawings, film editing), the most common ones being related to facilitating communication (conversation with friends, shooting, listening to music).

Female students are more active on Facebook, as they check their personal page more often at school and / or at work, read more posts, and like posts and photos. There are no differences regarding these activities from the perspectives of the faculty profile. Although they declare that they use the smartphone for learning, the leisure activities are better represented, confirming other findings (e.g. Lepp et al., 2015).

Unlike other studies (e.g., Hew, 2011), we found that academic performance expressed through the GPA is decreasing for students browsing other Facebook users' profiles or searching for their friends. This indirectly confirms the hypothesis of the relationship between loneliness and the use of this application, confirming other studies (e.g. Junco, 2012).

The findings of these studies must be used with cautions because the samples are accidental and the data is self-reported. For future research, we propose to use more variables or a qualitative approach. Comparing attitudes dynamics at various 
ages, including adults employees can provide interesting data that can be used in effective educational interventions or training.

\section{General conclusions and implications}

Using the internet and the computer has definite benefits as far as learning is concerned: lower costs, enhancement of teaching and learning, increase in the access to good quality courses etc. Smartphones and social networking facilitate access to information, communication, reduce boredom and loneliness. But the negative effects are also present.

Our findings distance themselves from the findings obtained in other cultures and in the previous decades: although the anxiety towards the computer and the internet are not equal among genders, being lower in the case of males and younger students, the self-efficacy towards them is equal. So the self-efficacy can be a premise for reducing the anxiety towards these devices. From a psychological perspective, the equivalence of the self-efficacy level for female and male students confirms the assumption of the multidimensional nature of this construct and. From a pedagogical perspective, the equal level of attitudes is probably favoured by the learning objectives and opportunities offered by the educational system.

The more favourable attitudes towards the internet and the lesser anxiety for students in the Science profile reconfirm the positive impact of competencies, developing an argument for an optimistic assumption. Male students and students enrolled in Sciences report they use the smartphone for learning more, compared to the ones enrolled in Humanities. However, applications that require significant cognitive demand are less used by all participants (e.g. creating animations and drawings, editing movies), the most commonly used being the social and leisure time ones (conversations with friends, shooting, listening to music). Editing photos and synchronising the smart phone with the PC are used more by the male students. Task switching, an activity incriminated for reducing learning efficiency, is present in the investigated sample more frequently in the case of Humanities students, but it does not correlate with academic performance.

The explosion of social networks has not only positive effects that meet basic needs (group acceptance and impression management), but for some activities it can reduce academic performance. The need to reduce computer anxiety is also supported by its negative association with academic performance in ICT subjects. Both types of results indicate the need to know the students' attitudes and behaviours, and to intervene in order to reduce excesses and increase positive effects. Both categories of results highlight the negative effects of the computer, the internet and the smartphone, but their benefits cannot be totally denied. These benefits only occur for students and teachers if the level of anxiety and addiction to the computer, the internet and the smartphone can stimulate learning and well-being.

\section{References}

[1] Allport, G.W. (1935). Attitudes. In Handbook of social psychology, pp. 798-844. C. Murchison, Worcester, MA: Clark Univ. Press.

[2] Cocoradă, E., \& Pălăşan, T. (2014). Computer Anxiety and self-efficacy for highschool students: The International Scientific Conference Elearning and Software For Education, 3, 90-95. Bucharest: „Carol I" National Defence University.

[3] Compeau, D. R., \& Higgins, C.A. (1995). Computer Self-Efficacy: Development of a Measure and Initial Test. Management Information Systems Quarterly, 19(2), 189-211.

[4] Cooper, J. (2006). The digital divide: The special case of gender. Journal of Computer Assisted Learning, 22(5), 320-334.

[5] Deryakulu, D., \& Calışkan, E. (2012). A twin study of computer anxiety in Turkish adolescents. Cyberpsychol Behav Soc Netw, 15(4), 212-218.

[6] Dixit, S., Shukla,H., Bhagwat, A. K, Bindal, A., Goyal, A., Zaidi, A. K, \& Shrivastava, A. (2010). A Study to Evaluate Mobile Phone Dependence among Students of a Medical College and Associated Hospital of Central India. Indian Journal of Community Med, 35(2), 339-341.

[7] Forrester Research (2016). 2016-The State of Retailing Online 2016: Key Metrics, Business Objectives and Mobile. Retrieved from https://nrf.com/resources/retail-library/state-of-retailing-online.

[8] Gosling, S. D., Augustine, A. A., Vazire, S., Holtzman, N., \& Gaddis, S. (2011). Manifestations of Personality in Online Social Networks: Self-Reported Facebook-Related Behaviors and Observable Profile Information. Cyberpsychology, Behavior, and Social Networking, 14(9), 483-488. http://doi.org/10.1089/cyber.2010.0087 
[9] Heinssen, R. K., Glass, C. R., \& Knight, L. A. (1987). Assessing computer anxiety: Development and validation of the computer anxiety rating scale. Computers in Human Behavior, 3, 49-59.

[10] Hew, K. F. (2011). Students' and teachers' use of Facebook. Computers in Human Behavior, 27(2), 662-676. http://doi.org/10.1016/j.chb.2010.11.020

[11] Institutul National de Statistică. [National Institute of Statistics] (2013b). Accesul populaţiei la tehnologia informaţiilor şi comunicaţiilor în anul 2013. [People's access to technology of information and communication in 2013]. Retrieved from http://www.insse.ro/cms/files/ statistici/comunicate/ com_anuale/tic/tic_r2013.pdf

[12] Junco, R. (2015). Student class standing, Facebook use, and academic performance. Journal of Applied Developmental Psychology, 39, 18-29.

[13] Lepp, A., Barkley, J. E., \& Karpinski, A. C. (2015). The Relationship Between Cell Phone Use and Academic Performance in a Sample of U.S. College Students. SAGE Open, 5(1). http://doi.org/10.1177/2158244015573169

[14] Liaw, S. S. (2002). An Internet survey for perceptions of computers and the World Wide Web: relationship, prediction, and difference, Computers in Human Behavior, 18(1), 17-35.

[15] Marcoulides, G. A, Cavus, H, Marcoulides, L. D, \& Gunbatar, M. S. (2009). Predictors of computer anxiety: a factor mixture model analysis. Psychological Report, 105(3), 687-696.

[16] Mayudia, N., Mothar, M., Musa, P., Hassan, B. A., Salleh, P., Hassan, B. H., \& Osman, M. N. (2013). The Importance of Smartphone's Usage Among Malaysian Undergraduates. IOSR Journal of Humanities and Social Science, 14(3), 112-118.

[17] Muscanell, N. L., \& Guadagno, R. E. (2012). Make new friends or keep the old: Gender and personality differences in social networking use. Computers in Human Behavior, 28(1), 107-112.

[18] Nickell, G. S., \& Pinto, J. N. (1986). The computer attitude scale, Computers in Human Behavior, 2, 301-306.

[19] Rosen, L. D., Whaling, K., Carrier, L. M., Cheever, N. A., \& Rokkum, J. (2013). The Media and Technology Usage and Attitudes Scale: An empirical investigation. Computers in Human Behavior, 29(6), 2501-2511. Retrieved from http://www.ncbi.nlm.nih.gov/pubmed/25722534

[20] Rotsztein, B. (2003). Problem Internet use and locus of control among college students: Preliminary findings. The 35th Annual Conference of the New England Educational Research Organization Portsmouth, New Hampshire, April 10, 2003.

[21] Rung, A., Wranke, F., \& Mattheos, N. (2014). Investigating the use of smartphones for learning purposes by Australian dental students. JMIR Mhealth Uhealth, 2(2), e20.

[22] Weil, M. M., Rosen, L. D. (1995).The psychological impact of technology from a global perspective: A study of technological sophistication and technophobia in university students from twenty-three countries. Computers in Human Behavior, 11(1) 95-133.

[23] Wohn, D. Y., \& Larose, R. (2014). Effects of loneliness and differential usage of Facebook on college adjustment of first-year students. Computers and Education, 76, 158-167. DOI: 10.1016/i.compedu.2014.03.018

[24] Xu, R., Frey, R. M., Fleisch, E., \& llic, A. (2016). Understanding the impact of personality traits on mobile app adoption - Insights from a large-scale field study. Computers in Human Behavior, 62, 244-256. http://doi.org/10.1016/i.chb.2016.04.011 